\section{EL BIODERECHO Y LA PROTECCIÓN JURÍDICA DE LA VIDA: EL CASO DEL ABORTO}

\author{
Ignacio Sánchez Cámara \\ Universidad Católica de Valencia \\ ORCID iD: https://orcid.org/0000-0003-0204-6734 \\ ignacio.sanchezcamara@ucv.es
}

Cómo citar este artículo/Citation: Sánchez Cámara, I. (2019). EI bioderecho y la protección jurídica de la vida: el caso del aborto Arbor, 195(792): a508. https://doi.org/10.3989/arbor.2019.792n2009

Recibido: 30 septiembre 2015. Aceptado: 28 abril 2016.

RESUMEN: La solución de los problemas biojurídicos depende fundamentalmente de la concepción del derecho y de la valoración de la vida humana de la que se disponga. La supresión de la perspectiva de la justicia, unida a la consideración de la vida humana como mera propiedad inmanente de un ser vivo que, en el caso del hombre, permitirá la libre disposición de ella, conducirá necesariamente a una degradación de la protección jurídica de la vida. Por el contrario, la vinculación del derecho con la moral, a través de la justicia, propia de la concepción óntico-valorativa o, al menos, de una concepción del derecho que aúne las tres dimensiones, conducirá a una más firme defensa jurídica de la vida. Desde esta perspectiva se analiza la desprotección jurídica, y por tanto moral, de la vida en la regulación del aborto en la legislación española.

PALABRAS CLAVE: Bioderecho; aborto; protección jurídica de la vida; justicia; defensa jurídica de la vida.

\section{BIOLAW AND LEGAL PROTECTION OF LIFE: THE CASE OF ABORTION}

Copyright: (c) 2019 CSIC. Este es un artículo de acceso abierto distribuido bajo los términos de la licencia de uso y distribución Creative Commons Reconocimiento 4.0 Internacional (CC BY 4.0).

ABSTRACT: The possibility of finding a correct solution for biolegal issues depends dramatically on two factors: our conception of law, and the value we confer to human life itself. Currently, we are witnessing a degradation of the concept of justice, as well as a reduction of the notion of human life to a mere immanent property of a living being. In these conditions, human life soon becomes a freely disposable item, and a demotion of the legal protection of life seems equally unavoidable. On the contrary, when law and morality are interconnected by means of the notion of justice, in an onticevaluative approach, a stronger legal protection of human life is achieved. Taking in account these ideas, here we assess the current lack of a legal and moral protection of human life in the Spanish regulation of abortion.

KEYWORDS: Biolaw; abortion; legal protection of life; justice; legal defense of life. 


\section{QUÉ ES EL BIODERECHO}

Quizá corresponda a la filosofía del derecho responder a dos preguntas fundamentales: ¿qué es el derecho? y ¿cómo debe ser el derecho ${ }^{1}$ Entonces cabría afirmar que dos son las preguntas que debe responder una posible filosofía del bioderecho: ¿qué es el bioderecho? y ¿cómo deber ser el bioderecho?

La expresión bioderecho significa la parte del derecho que se refiere primariamente a la protección jurídica de la vida humana. El bioderecho es al derecho lo que la bioética es a la ética: una parte del derecho y una parte de la ética. Si hablamos de bioética, hablamos de ética; y si hablamos de bioderecho, hablamos de derecho. Marta Albert afirma: "La bioética podría definirse como el conjunto de acciones debidas o exigibles en relación a la vida humana. Dentro de este conjunto de acciones exigibles, algunas de ellas serían debidas "jurídicamente" y otras, "moralmente" (Albert, 2015, p. 2273)².

También cabe hablar de biomoral. Ética y moral pueden ser términos intercambiables, con independencia de las diferencias derivadas de sus respectivas etimologías griega y latina. Si se hace distinción, se trataría de reservar el término ética para la disciplina o parte de la filosofía que se refiere a la moral, y el de moral para un determinado código de principios, valores o normas. Bioética sería entonces la disciplina o parte de la ética y biomoral la parte de la moral referida a la vida. En cualquier caso "en el debate biojurídico está en juego el futuro del derecho mismo" (Albert, 2015 , p. 2285). También se habla de biopolítica como un ámbito distinto de la bioética y de la biomoral. Andrés Ollero titula "Bioética, Bioderecho, Biopolítica" el prólogo a su libro Bioderecho. Entre la vida y la muerte (Ollero, 2006). Y Francesco D'Agostino es autor de una buena introducción a la biopolítica (D'Agostino, 2009). Estas recientes disciplinas se ocupan moral, jurídica o políticamente de los problemas relacionados con la vida. Entre ellos, el aborto (al que me voy a referir especialmente en este trabajo), la eutanasia, la pena de muerte, la experimentación con embriones humanos, la reproducción asistida, la fecundación artificial y otros, a los que se podrían añadir el hambre y la pobreza, el terrorismo y algunos más.

La concepción acerca del bioderecho dependerá entonces de la concepción que se tenga del derecho. Existen tres principales concepciones acerca del derecho. Según José María Rodríguez Paniagua son la estatal-formalista, la sociológico-realista y la ónticovalorativa (Rodríguez Paniagua, 1985, pp. 11-23). Las tres vienen a coincidir con el positivismo jurídico, el realismo sociológico y el iusnaturalismo (García Maynez, 1977). Para la primera, el derecho es, ante todo, ley estatal y todo aquello que ella integra. Para la segunda, el derecho es, ante todo, hecho social y, más específicamente, resolución de conflictos, sentencia judicial. Para la tercera, el derecho es, ante todo, la justicia. Cada una de estas tres concepciones defiende un determinado ideal que el derecho realiza o debe realizar. El ideal de la primera concepción es la certeza o seguridad jurídica. El de la segunda, la satisfacción de las necesidades o bienestar social. Y el de la tercera, la justicia (Rodríguez Paniagua, 1985). En realidad las tres dimensiones o aspectos han de ser tenidos en cuenta, pues el derecho es tanto ley como sentencia, como realización o, al menos, aspiración a la justicia. Además, las tres resultan compatibles entre sí. En este sentido, "pueden ser armonizadas en una síntesis, que podríamos expresar diciendo que el Derecho es un orden de la conducta humana, generalmente acatado en una determinada sociedad, porque, junto a la certeza y seguridad, trata de realizar otras aspiraciones, y dentro de éstas, de manera destacada, la justicia" (Rodríguez Paniagua, 1985, p. 22).

La disputa entre el iusnaturalismo y el positivismo se encuentra en la base de la definición o concepto del derecho. La expresión derecho natural resulta confusa pues "está montada sobre un doble equívoco, ya que en ella no tiene un sentido preciso ni la palabra derecho ni la palabra natural" (Rodríguez Paniagua, 1985, p. 79). La expresión derecho natural deriva de una mala o defectuosa traducción del griego por parte de los juristas romanos, al menos de los redactores del Corpus luris o de sus interpoladores. Los filósofos griegos, por ejemplo Aristóteles, hablaban de dykaion, que significa 'lo justo' (iustum) y no 'derecho' (ius). Así, lo justo por naturaleza no es equivalente a derecho natural. Pero si hay ambigüedades en el término derecho, aún hay más en el término natural (Wolf, 1950). El concepto de naturaleza no tiene hoy, a diferencia del de los griegos, un sentido ideal o valorativo (Rodríguez Paniagua, 1985, pp. 80 ss.). Pero nada de esto entraña ninguna argumentación en favor del positivismo jurídico, que es radicalmente erróneo. En realidad, el positivismo jurídico (y no, ciertamente, la democracia) se fundamenta necesariamente en el relativismo ético. Hans Kelsen acierta en lo primero, en fundamentar el positivismo jurídico en el relativismo ético, pero no en lo segundo, en fundamentar la democracia en el relativismo (cf. Kelsen 2006, pp. 222 y ss.). Ningún defensor de la verdad moral ( $y$, por lo tanto, de la verdad de la justicia) puede ser positivista. 
No obstante, también cabría hacer matizaciones a la tesis de la identificación entre derecho y justicia. En favor de la primera de las tres concepciones acerca del derecho mencionadas antes, hay que reconocer que no hay derecho sin ley. Pero, en contra de ella, que el derecho no es solo ley. En favor de la segunda de las concepciones, hay que admitir que no hay derecho sin resolución de conflictos o sentencia judicial, pero en contra, que el derecho no es solo sentencia judicial. Ambas, ley y sentencia, son condiciones necesarias, pero no suficientes de la existencia del derecho. La pretendida pureza del derecho, la búsqueda de una única esencia del derecho, parece fracasar. La realidad del derecho parece ser plural o poliédrica: es norma, pero necesitada de interpretación; es también principio y aplicación; es ponderación, jurisprudencia; es arte y prudencia; y es, sobre todo, justicia, búsqueda de la justicia. Si hubiera que buscar un elemento dominante o predominante, ese sería la justicia. La finalidad del derecho, su sentido y razón de ser es la búsqueda incesante, y siempre provisional, de la justicia.

\section{2. ¿ES EL ABORTO UN DERECHO?}

Aunque la maldad moral del aborto parece evidente, existen, no obstante, notables dificultades argumentativas para criticarlo en el ámbito jurídico y político. Cabría plantearlo así. En el ámbito moral, se pretende que todo es discutible. En el jurídico y político, la libertad obligaría a su permisión, puesto que nadie resultaría obligado y permitiría que todos ejercitaran su libertad. No obstante, cabría hacer una reflexión previa sobre la cuestión moral, pues no es evidente, ni cierto, que aquí todo sea opinable y discutible. No es razonable asumir como propia una posición que no se comparte, y que ni siquiera es evidente que sea la dominante, la mayoritaria. Me refiero a esa amalgama de relativismo, convencionalismo, utilitarismo, emotivismo y hedonismo. Con frecuencia, se impone como neutral regla de juego lo que entraña la asunción de la verdad de una de las posiciones enfrentadas. Y la cuestión moral, aunque no predetermine la solución jurídica, sí puede condicionar su solución. Si, por ejemplo, el aborto se equipara al homicidio en lugar de asimilarse a un deber estrictamente religioso como, por ejemplo, la obligación de asistir a la misa dominical para los católicos, la cosa no dejará de tener consecuencias para su regulación jurídica.

Conviene eludir las meras discusiones sobre palabras. En su segunda carta a Timoteo, san Pablo afirma: "Esto has de enseñar; y conjura en presencia de Dios que se eviten las discusiones sobre palabras, que no sirven para nada, si no es para perdición de los que las oyen". Por lo demás, conviene atender a la advertencia de Popper, según la que no es posible cambiar mediante argumentos la opinión a la que no se ha llegado mediante argumentos.

Sin embargo, tampoco faltan razones a favor de un posible entendimiento entre las concepciones religiosas y metafísicas (cristianas) y las laicistas y progresistas, pues existe un trasfondo cultural común. Democracia, liberalismo y cristianismo se encuentran íntimamente vinculados (Bellver Capella, 2014).

En este sentido, conviene rechazar la falsa tesis que pretende que la democracia se fundamenta en el relativismo moral y que, por lo tanto, toda posición que asuma la existencia de valores objetivos o universales sea incompatible con la democracia. Ni la democracia ni el derecho dirimen cuestiones sobre la verdad moral. El parlamento legisla, pero no dictamina sobre la verdad moral (Sánchez Cámara, 2015).

En realidad, y en contra de lo que con frecuencia se pretende hoy, hay que afirmar la relatividad del derecho y el absolutismo de la moral. Mientras el derecho es relativo, la moral aspira a ser absoluta. Como afirma Marta Albert, siguiendo a Max Scheler, "el relativista no es, en el fondo, más que el absolutista de lo relativo" (Albert, 2009, p. 46). La idea scheleriana de "lo bueno es sí para mí" no es relativista "porque aquello que se conoce como bueno, es bueno en sí", aunque pueda serlo solo "para mí". En nuestro tiempo tiende a pensarse erróneamente que el derecho viene a ser algo así como una moral mínima, única, que debe ser compartida, mientras que la moral pertenece al ámbito de la arbitrariedad de la conciencia.

Partiendo, que no necesariamente asumiendo, de la perspectiva del liberalismo clásico, quizá convenga recordar sus raíces: el socratismo, el cristianismo y la concepción personalista del derecho de los germanos. El liberalismo no es un invento moderno. Tiene raíces antiguas y medievales. La idea socrática de que la verdad puede encontrarse a través de la razón es el germen de la idea de libertad. El cristianismo postula la idea de que la verdad se encuentra en el hombre interior (San Agustín) y distingue entre los dos poderes: el espiritual y el temporal. La concepción del derecho de los germanos no es individualista ni colectivista sino personalista. De esas tres raíces procede el liberalismo clásico que triunfa en el mundo moderno.

Se trataría entonces de buscar argumentos en contra de la legalización del aborto libre incluso en el 
ámbito de la filosofía jurídica y política de orientación liberal. ¿Es el aborto un derecho? ¿Puede ser considerado legítimamente como un derecho? Vivimos un tiempo de apoteosis de los derechos y de declive de los deberes. Pero sin deberes no son posibles los derechos. Primero, porque para tener derechos es preciso cumplir los propios deberes. Segundo, porque tener un derecho incluye el deber de los demás de garantizarlo y respetarlo. Es frecuente confundir la idea de lo jurídicamente lícito o permitido con la existencia de un derecho. No existe un derecho a todo lo que no está prohibido. Lo no prohibido está permitido, pero no existe un derecho a realizar todo lo jurídicamente permitido. Tener un derecho es tener la capacidad de obligar a todos los demás, de comprometer a toda la sociedad en el ejercicio y garantía del mismo. Decía Kant que tener un derecho (subjetivo) es tener la capacidad de constreñir. Es decir, que aun en el supuesto de que el aborto no fuera castigado en ningún caso como delito, es decir, que estuviera totalmente despenalizado, eso no significaría necesariamente que hubiera un derecho al aborto. De hecho, en la legislación española anterior, el aborto era, en general, un delito, pero no se aplicaba la pena en tres supuestos. Pero en esos tres casos, no se configuraba como derecho, sino solamente como una conducta no penada. Un derecho es una conducta respaldada por la fuerza legítima del estado y, por lo tanto, algo cuya realización se puede reclamar e imponer. Por eso tampoco es correcto identificar el derecho con la existencia de una necesidad o de un deseo de una persona o de un grupo. Esta hipertrofia de los derechos conduce, de hecho, a su devaluación, pues tener derecho a (casi) todo es lo mismo que no tener derecho a (casi) nada.

Una de las interpretaciones del liberalismo lo vincula con la neutralidad del estado. Dado que existen diferentes concepciones sobre la realidad y sobre la vida, y especialmente diferentes concepciones religiosas y morales, la exigencia liberal sería que los poderes públicos mantuvieran la más estricta neutralidad hacia ellas, impidiéndose cualquier preferencia hacia ninguna de ellas. Pero esta neutralidad probablemente no sea posible ni deseable. Lo primero, porque no es posible gobernar con una absoluta neutralidad. Gobernar es optar y decidir a favor de unas políticas en detrimento de otras. No cabe un gobierno ideológica o moralmente neutral. Lo mismo que no es posible una educación neutral y libre de valores. Pero, aunque fuera posible, no sería tampoco deseable, pues no es correcto mantenerse neutral ante fines, objetivos y valores de diferente rango, y menos aún entre los valores y los contravalores. No es lícita una neutrali- dad entre el bien y el mal, entre lo noble y lo abyecto. Frente a la neutralidad liberal, existe otra concepción del liberalismo que ha sido calificada como perfeccionista. El liberalismo no tiene por qué asumir el relativismo ético y cultural y la consiguiente indiferencia hacia las diferentes concepciones morales de la vida.

Muy influyente en la tradición liberal, aunque algo en declive en nuestro tiempo, es el criterio que John Stuart Mill estableció en su ensayo Sobre la libertad, para establecer cuándo la intervención de la sociedad mediante la fuerza sobre la conducta de una persona es o no legítima. Ese criterio es el principio del daño. Ni la sociedad, ni otro hombre o grupo, ni el estado pueden obligar a alguien a hacer o no hacer algo a menos que, de no hacerlo, se produzca un daño para alguien. En todo lo demás, el individuo es, de hecho y de derecho, soberano ${ }^{3}$. Al margen de los problemas que este criterio pueda plantear al ser interpretado y aplicado, lo cierto es que no se trata de un criterio moral sino social, jurídico y político. No es que sea correcto moralmente todo lo que no dañe o perjudique a los demás. Mill no defiende una neutralidad valorativa acerca de las diferentes formas de vida. Se trata solo de evitar la imposición de los demás y preservar así la libertad que era, para él, la condición del progreso social.

Otro de los rasgos de la filosofía política dominante es la hipertrofia del principio de autonomía de la voluntad, principio que, de suyo y en sus justos límites, es bueno y correcto. Vinculada a él se encuentra también la consideración de la autenticidad como el supremo, o único, criterio o principio moral. Estos excesos de la autonomía y de la autenticidad pueden comprobarse, entre otros, en el caso de la eutanasia. No existe libertad ni autonomía para quitarse la propia vida, ni menos aún para configurar esa acción como un derecho. No hay libertad para matar. La libertad no es absoluta, ni siquiera para el liberalismo más radical. No lo es tampoco en otros ámbitos ajenos a la vida. En realidad, en ningún ámbito lo es.

$Y$ ya que tanto se habla de derechos convendría no olvidar los derechos de los más débiles, entre los que se encuentra, sin duda, el embrión. En este sentido, cabe recordar un memorable artículo publicado en 1986 en ABC por Miguel Delibes, con el título "Aborto libre y progresismo". Se discute si el feto es o no es un ser portador de derechos y deberes desde el instante de la concepción. "Yo creo que esto puede llevarnos a argumentaciones bizantinas a favor y en contra, pero una cosa está clara: el óvulo fecundado es algo vivo, un proyecto de ser, con un código 
genético propio que con toda probabilidad llegará a serlo del todo si los que ya disponemos de razón no truncamos artificialmente el proceso de viabilidad. De aquí se deduce que el aborto no es matar (parece muy fuerte eso de calificar al abortista de asesino), sino interrumpir vida; no es lo mismo suprimir a una persona hecha y derecha que impedir que un embrión consume su desarrollo por las razones que sea. Lo importante en este dilema es que el feto aún carece de voz, pero, como proyecto de persona que es, parece natural que alguien tome su defensa, puesto que es la parte débil del litigio".

Por eso le parecía al gran escritor paradójico que fueran precisamente los progresistas, que alardean de defender la causa de los más débiles, quienes en este caso olviden a la parte más débil e indefensa: al embrión.

\section{LA PROTECCIÓN JURÍDICA DE LA VIDA}

La vida humana no es un valor absoluto (Sánchez Cámara, 2012). Si lo fuera, carecería de sentido moral la entrega de la propia vida a favor de un valor o de un ideal. Así lo expresó el cardenal Belarmino en su crítica a la filosofía política de Hobbes. Según él, las ideas del filósofo inglés serían válidas si la conservación de la vida fuera un valor absoluto, pero no lo es. No es lícito conservar la vida a toda costa. En ocasiones, puede y debe ser entregada para el cumplimiento de un fin superior. Esto no impide que la vida humana constituya un bien fundamental que debe ser protegido por la moral y el derecho. Pero, aunque no sea un valor absoluto, sí es un derecho fundamental e, incluso, fundamento de todos los demás derechos, pues todos ellos dependen y se fundamentan en el derecho a la vida.

Así, entre los derechos fundamentales siempre se menciona, muchas veces como el primero de todos ellos, el derecho a la vida. Pero la situación de los derechos humanos en nuestro tiempo es sumamente paradójica. Por un lado, parece recaer sobre ellos una especie de acuerdo general, como si, por fin, hubiéramos alcanzado el viejo sueño del consenso moral y jurídico universal. Pero, por otro, el acuerdo deviene puramente aparente. Como expresó uno de los redactores de la Declaración Universal de Naciones Unidas, logramos el acuerdo con la condición de prescindir de la cuestión del fundamento. Pero esta cuestión, aparte de su intrínseca relevancia, afecta al problema del contenido. Así, no entienden del mismo modo el derecho a la vida quienes, por ejemplo, la entienden como un don de Dios, indisponible, por tanto, para su titular, que quienes lo consideran como una mera propiedad intrínseca a ciertos seres, que llamamos vivos, acaso disponible entonces por su titular. Mientras unos incluyen dentro del derecho a la vida la prohibición del aborto, la eutanasia o la pena de muerte, otros consideran su permisión como compatible con él. El acuerdo versa entonces solo sobre una expresión. No existe verdadero acuerdo. Así, los derechos humanos se convierten en una especie de retórica o ideología, válida para los debates y luchas políticos. Sin la cuestión del fundamento, los derechos quedan, como no podía ser de otro modo, sin fundamento, es decir, sin verdaderas razones para su defensa. $Y$ además queda afectado su contenido, abierto a las discrepancias (Sánchez Cámara, 1999).

No cabe duda de que la protección jurídica (prescindiré, al menos de momento, de la protección moral) de la vida es un asunto decisivo. Quisiera sugerir aquí que la protección jurídica de la vida está sufriendo un grave declive en el derecho español. Uno de sus aspectos decisivos es la actual regulación del aborto. La regulación anterior tipificaba en el código penal el aborto voluntario como delito, y en tres supuestos excluía la aplicación de la pena: en caso de embarazo producido como consecuencia de una violación; cuando existían graves malformaciones en el feto; y en caso de grave peligro para la salud física o psíquica de la mujer. Se trataba, quizá, de una solución de compromiso entre las posiciones de quienes eran partidarios de la penalización en todos los casos y los defensores de la exclusión de la protección penal. No era una solución perfecta pero sí razonable. Lo cierto es que años de experiencia condujeron a la despenalización de facto, sobre todo por la vía del fraude de ley en el supuesto de la salud psíquica de la madre. De hecho, se trataba, en contra de la ley, del aborto libre. Al menos, quedaba en pie el principio de que el aborto era un delito. En cualquier caso, no existía en nuestro ordenamiento un derecho al aborto, sino solo la exceptuación de la aplicación de la sanción penal en tres supuestos concretos.

La actual regulación supone un cambio radical en el derecho español sobre esta materia (Albert, 2013). Para empezar, entraña la asunción del eufemismo, lo que, de por sí, supone el reconocimiento de la mala conciencia. No se habla de aborto ni de eliminación de la vida embrionaria, sino de "interrupción voluntaria del embarazo". Extraña formulación que podría sugerir la continuación del proceso gestatorio después de la interrupción, pues lo que se interrumpe puede ser, al menos en ocasiones, continuado ${ }^{4}$. Se trata de hacer invisible lo visible, pero pequeño. No es extraño 
que sus partidarios se indignen cuando sus adversarios pretenden la visibilidad del embrión y la patencia de lo que es una eliminación de vidas humanas. Verlo es, entonces, algo truculento y de mal gusto, cuando se trata de la realidad misma.

Tampoco deja de ser un reconocimiento, acaso involuntario, de culpa la inclusión de la reforma en una ley sobre "la salud sexual y reproductiva de la mujer". Se trata de convencer a convencidos o a incautos de que la ley no persigue la legalización de la eliminación el embrión, sino solo proteger la salud de la mujer. Aunque para ello haya que sostener lo insostenible: que la muerte del embrión entrañe la protección de la salud sexual y reproductiva de la mujer.

$\mathrm{Y}$, por si esto fuera poco, se sostiene que la reforma no entraña un cambio radical, sino solo la obtención de los beneficios de la seguridad jurídica. Seguridad, sí, pero a qué precio. Lo que era un delito pasa a convertirse en un derecho (Albert, 2013). La reforma va mucho más allá de la mera despenalización (González Marsal, 2009). No cabe mayor ni más radical cambio. $Y$ aun esto se hace de manera vergonzante. Ya se sabe que la hipocresía es el tributo que el vicio rinde a la virtud. Incluso se niega que se configure como derecho. El texto desenmascara, incluso explícitamente, la impostura. El artículo 18 , bajo el título "Garantía del acceso a la prestación" (el aborto es una prestación sanitaria, como el tratamiento de una caries) establece:

"Los servicios públicos de salud, en el ámbito de sus respectivas competencias, aplicarán las medidas precisas para garantizar el derecho a la prestación sanitaria de la interrupción voluntaria del embarazo en los supuestos y con los requisitos establecidos en esta Ley. Esta prestación estará incluida en la cartera de servicios comunes del Sistema nacional de Salud".

No hay duda. El aborto es una prestación sanitaria y una exigencia de la salud. Pero además es un derecho: "para garantizar el derecho a la prestación sanitaria de la interrupción voluntaria del embarazo". Quienes niegan que se configure como derecho o ignoran (culpablemente, pues el texto está ahí, claro y rotundo) o mienten. Que cada cual se acoja a la alternativa que proceda. Algún cauteloso aún pretenderá que solo es un derecho "en los supuestos y con los requisitos establecidos en esta Ley". Ya es terrible que el aborto pueda ser un derecho en algún supuesto, pero los términos de la ley son ilimitadamente amplios, pues la mujer embarazada puede decidir la interrupción del embarazo, es decir, la muerte de su hijo embrionario, en las primeras catorce semanas, sin invocar ningún motivo. En ese plazo, el aborto libre es un derecho de la mujer.

Como afirma Kant, tener un derecho subjetivo es tener la capacidad de constreñir $u$ obligar a otros. $Y$, en palabras de lhering, estar en posesión de un interés jurídicamente protegido (Ihering, 1998, p. 1033). Todo derecho genera el deber de satisfacerlo. Hay que distinguir entre la existencia de un derecho y la de lo meramente lícito o permitido, es decir, aquello que el derecho no prohibe pero tampoco impone como algo exigible. En suma, no tenemos derecho a todo lo no prohibido.

"El aborto puede estar prohibido, ser un acto lícito o convertirse en un derecho. Sólo en este último caso, la mujer tendrá la capacidad de exigir del Estado la realización de la "prestación sanitaria", y el Estado tendrá el correlativo deber de garantizar esa prestación" (Albert, 2013). La despenalización no se identifica en teoría con la legalización. Cabe un delito sin sanción, pero esto no deja de ser una institución jurídica bastante anómala. En la práctica la legalización y la despenalización suelen entenderse como expresiones sinónimas (Serrano Ruiz-Calderón, 2005, p. 164).

$Y$ que se configure o no como un derecho es fundamental en sí y también para determinar su constitucionalidad, pues si se configura como derecho parece evidente que habría que concluir afirmando la inconstitucionalidad de la norma que así lo configure. Esto queda patente en los informes que fueron emitidos durante el proceso de elaboración de la norma (Albert, 2013, pp. 94 ss.). En cualquier caso, resulta claro que en nuestro ordenamiento jurídico no es posible reconocer la existencia de un derecho al aborto (Ollero, 2010, 31 de enero). Resulta claro que la actual legislación sobre el aborto es inconstitucional en la medida en que establece la existencia de un derecho al aborto. Quienes defienden su constitucionalidad niegan que consagre un derecho al aborto; y quienes defienden su inconstitucionalidad consideran que sí lo consagra. Al menos en este sentido, todos coinciden: si se constituye como derecho sería inconstitucional. Por lo tanto, la consideración del aborto como derecho sería, en cualquier caso, inconstitucional (Albert, 2013, p. 100). Así lo expresa Fernando Abellán:

"En cualquier caso, más allá de los aspectos formales de técnica legislativa, no cabe duda de que el régimen que consolida la ley de la que estamos hablando, previendo un plazo de total libertad de la mujer para abortar, y una obligación de la Administración pública de garantizar y costear la práctica del aborto, equivale 
en la práctica a un auténtico derecho al aborto. No puede decirse que en este caso estemos en presencia de una mera manifestación de libertad (esto es, del agere licere o libertad de hacer generada al amparo de la necesidad de respetar la voluntad ajena), sino que en la medida en que la decisión de la mujer de abortar genera inmediatamente y de forma paralela una obligación del poder público de materializar dicha voluntad y de poner los medios para la realización del aborto deseado, estamos en el terreno propio de los derechos subjetivos" (Abellán, 2010, p. 130).

Cabe esgrimir un argumento más, relativo a la objeción de conciencia introducida por la ley:

“Cabría añadir, más allá de lo señalado, que la misma regulación de la objeción de conciencia del personal sanitario que introduce la ley es una prueba de la existencia de un derecho al aborto. Si la mujer no tuviera derecho a abortar, no surgiría en ningún profesional de la salud el deber de practicar el aborto, luego no podríamos hablar de objeción de conciencia, puesto que los profesionales no tendrían, en sentido estricto, ningún deber que objetar" (Albert, 2013, p. 102).

\section{EL ABORTO EN LA ACTUAL LEGISLACIÓN ESPAÑOLA}

El artículo 14, bajo la rúbrica "Interrupción del embarazo a petición de la mujer", no ofrece espacio para la duda:

"Podrá interrumpirse el embarazo dentro de las primeras catorce semanas de gestación a petición de la embarazada, siempre que concurran los requisitos siguientes:

a) Que se haya informado a la mujer embarazada sobre los derechos, prestaciones y ayudas públicas de apoyo a la maternidad, en los términos que se establecen en los apartados 2 y 4 del artículo 17 de esta Ley.

b) Que haya transcurrido un plazo de al menos tres días, desde la información mencionada en el párrafo anterior y la realización de la intervención".

Además el artículo 12, bajo el ignominioso título de "garantía de acceso a la interrupción voluntaria del embarazo", establece:

"Se garantiza el acceso a la interrupción voluntaria del embarazo en las condiciones que se determinan en esta ley. Estas condiciones se interpretarán en el modo más favorable para la protección y eficacia de los derechos fundamentales de la mujer que solicita la intervención, en particular, su derecho al libre de- sarrollo de la personalidad, a la vida, a la integridad física y moral, a la intimidad, a la libertad ideológica y a la no discriminación".

No se trata, pues, de algo meramente lícito o permitido, que puede hacerse o no sin ser molestado, sino de algo que ha de ser garantizado. $Y$ si ha de ser garantizado, entonces es un derecho. Por lo demás, es llamativo (por no decir, indigno) que la muerte voluntaria del hijo embrionario pueda perpetrarse en beneficio del libre desarrollo de la personalidad de la madre o del derecho a su intimidad o a su libertad ideológica.

Además, el estado se ve obligado a asumir el comprometido papel de garantizar el ejercicio del derecho a la práctica del aborto hasta la decimocuarta semana de la gestación y perseguir esta acción como delictiva un día después de superado este plazo. El trascurso de un día convierte un derecho en un delito (Requero Ibáñez, 2009, p. 489).

Dejando de lado las cuestiones morales, podemos seguir centrándonos en las jurídicas. El código civil establece que al concebido y no nacido se le tiene por nacido para todos los efectos que le sean favorables. Así, podrá tener expectativas para heredar o recibir donaciones, pero no para vivir. Vivir ha dejado de ser un efecto favorable para el derecho español.

Parece que queda configurado en nuestro derecho algo así como un derecho a matar, pues que la madre decida sobre su maternidad una vez que el proceso gestatorio está en curso, es tanto como conferirle un derecho a eliminar la vida humana que crece en su seno. $Y$ aquí entran otras disquisiciones eufemísticas. ¿Es el embrión humano de pocas semanas un ser humano? Y se arguyen consideraciones científicas. ¿Científicas? La ciencia no resuelve cuestiones morales, pero suministra el conocimiento de los hechos. Privilegiar un determinado momento de la evolución embrionaria no deja de ser un expediente interesado. La ciencia no puede sino confirmar un hecho incontrovertible: la vida humana es un proceso continuo desde la fecundación hasta la muerte. Lo demás son palabras interesadas. Como aquellas pronunciadas por la entonces ministra de Igualdad, según las cuales, es indiscutible que el embrión es un ser vivo, pero es una cuestión disputada que sea un ser humano. Pero si es un ser vivo pertenecerá a una especie y, si como parece evidente, pertenece a la especie humana, un ser vivo que pertenece a la especie humana es un ser humano. A menos que haya seres vivos que no pertenezcan a ninguna especie, lo que no parece fácil de asumir por la ciencia (Aznar, 2013). 
Algunos invocan la existencia de un conflicto de derechos que debe ser resuelto "ponderadamente". Veamos. Está el derecho del embrión a la vida y el derecho de la mujer a decidir. Pero a decidir ¿qué? Naturalmente, el derecho a decidir sobre su salud o sobre su maternidad. Dejando de lado el eufemismo, el conflicto puede plantearse así: existe un conflicto entre el derecho a la vida del embrión y el derecho de la mujer a eliminarlo. Incluso planteado en tan cínicos términos, la solución legal no ofrece dudas. Prevalece, de manera absoluta, el derecho de la mujer a eliminarlo. La solución del "conflicto de derechos" resulta evidente.

Sigamos con el derecho. El artículo 15 de la Constitución establece que "todos tienen derecho a la vida". Cabe preguntar acerca de quiénes son esos "todos". Está claro que la norma fundamental evita la mención de la persona. Parece evidente que, dada la concepción civilista de la persona, que solo atribuye personalidad jurídica (la filosófica o moral es otra cosa) al nacido, la intención no puede ser otra que proteger al embrión. Desde luego, hubiera sido preferible otra formulación. Como el reconocimiento del derecho a la vida desde la concepción hasta la muerte. Acaso fue una fórmula de transacción. Pero, en cualquier caso, el "todos" no se refiere solo al ya nacido, pues entonces habría que haber optado por "toda persona". En cualquier caso, la Constitución consagra la protección de la vida, de toda vida. Así, el Tribunal Constitucional, aunque de manera insuficiente, ya que no le ha reconocido la condición de persona, ha establecido que el embrión es un bien digno de protección jurídica. Esta jurisprudencia ha sido vulnerada por la nueva legislación, a pesar de que sus promotores y defensores sostengan que, en ella, la vida del no nacido se encuentra suficientemente protegida. La pretensión de que la protección de la vida del no nacido quede garantizada por el consentimiento informado de la mujer es insostenible. La vida del embrión queda a merced de la arbitrariedad de la embarazada. Eso de ninguna manera se puede calificar como protección. Por lo demás, la regulación del consentimiento informado, que no constituye, de suyo, una garantía suficiente, está lejos de ser satisfactoria. Se encuentra regulado en el artículo 17. El punto 1 establece lo siguiente:

\footnotetext{
“Todas las mujeres que manifiesten su intención de someterse a una interrupción voluntaria del embarazo recibirán información sobre los distintos métodos de interrupción del embarazo, las condiciones para la interrupción previstas en esta Ley, los centros públicos y acreditados a los que se pueda dirigir y los
}

trámites para acceder a la prestación, así como las condiciones para su cobertura por el servicio público de salud correspondiente".

Así, lo primero que la mujer recibe es información sobre cómo satisfacer su voluntad de acabar con la vida de embrión. Esto no tiene nada que ver con el consentimiento informado, sino más bien con la ayuda para la consolidación de la decisión letal.

\section{El punto 2 aporta poco en la dirección de la reflexión:}

"En los casos en que las mujeres opten por la interrupción del embarazo regulada en al artículo 14 recibirán, además, un sobre cerrado que contendrá la siguiente información:

a) Las ayudas públicas disponibles para las mujeres embarazadas y la cobertura sanitaria durante el embarazo y el parto.

b) Los derechos laborales vinculados al embarazo y a la maternidad; las prestaciones y ayudas públicas para el cuidado y atención de los hijos e hijas; los beneficios fiscales y demás información relevante sobre incentivos y ayudas al nacimiento.

c) Datos sobre los centros disponibles para recibir información adecuada sobre anticoncepción y sexo seguro.

d) Datos sobre los centros en los que la mujer pueda recibir voluntariamente asesoramiento antes y después de la interrupción del embarazo.

Esta información deberá ser entregada en cualquier centro sanitario público o bien en los centros acreditados para la interrupción voluntaria del embarazo. Junto con la información en sobre cerrado se entregará a la mujer un documento acreditativo de la fecha de la entrega, a los efectos de lo establecido en el artículo 14 de esta Ley.

La elaboración, contenidos y formato de esta información será determinada reglamentariamente por el gobierno".

Esta información, a diferencia de la anterior, se dará en sobre cerrado. Toda la información pro aborto se da abiertamente, y la que pudiera disuadir de la decisión se dará en sobre cerrado. Por lo tanto, sin ninguna garantía de que pueda ser leída. La comparación con, por ejemplo, la legislación alemana en la materia, que también entraña una ley de plazos, es patente. Mientras la ley alemana promueve la reflexión de la mujer para evitar el aborto, la ley española favorece la decisión de abortar. El consentimiento informado en nuestra legislación apoya la decisión de la mujer a favor del aborto. 
Los puntos 3, 4 y 5 del artículo 17 no hacen sino confirmar esta tesis. En cualquier caso, no se puede sostener que el consentimiento informado de la mujer entrañe una protección suficiente de la vida del no nacido. Si a esto se añade su configuración legal como un derecho, que vincula a los poderes públicos y al Servicio nacional de Sanidad, es claro que la protección queda reducida a nada. Cabe extraer entonces la conclusión de que la nueva regulación vulnera el contenido del artículo 15 de la Constitución y resulta incompatible con la jurisprudencia constitucional sobre la materia. Es una cuestión de pura lógica jurídica: si existe un derecho a la vida, no puede haber un derecho a acabar con ella.

Estamos, pues, ante el aborto libre en el plazo de las primeras catorce semanas de la gestación. Pero hay más. También se puede practicar el aborto más tarde, "por causas médicas", en tres circunstancias (artículo 15):

“a) Que no se superen las veintidós semanas de gestación y siempre que exista grave riesgo para la vida o la salud de la embarazada y así conste en un dictamen emitido con anterioridad a la intervención por un médico o médica especialista distinto del que la practique o dirija. En caso de urgencia por riesgo vital para la gestante podrá prescindirse del dictamen.

b) Que no se superen las veintidós semanas de gestación y siempre que exista riesgo de graves anomalías en el feto y así conste en un dictamen emitido con anterioridad a la intervención por dos médicos especialistas distintos del que la practique o dirija.

c) Cuando se detecten anomalías fetales incompatibles con la vida y así conste en un dictamen emitido con anterioridad por un médico o médica especialista, distinto del que practique la intervención, o cuando se detecte en el feto una enfermedad extremadamente grave e incurable en el momento del diagnóstico y así lo confirme un comité clínico".

Por cierto, la ley no especifica la especialidad del médico. En esos supuestos tasados, el plazo se amplía a las veintidós semanas. La existencia de graves anomalías en el feto como supuesto del aborto permite introducir de hecho una especie de aborto eugenésico. Incluso en algunos casos no hay limitación de plazo; entre ellos, la detección de una enfermedad extremadamente grave e incurable en el feto.

Como no podía ser de otro modo, la consecuencia de esta regulación es la reforma necesaria de la formación de los profesionales de la salud y la introducción de modificaciones en el ámbito educativo. Así, el artículo 8 establece:
“La formación de profesionales de la salud se abordará con perspectiva de género e incluirá:

a) La incorporación de la salud sexual y reproductiva en los programas curriculares de las carreras relacionadas con la medicina y las ciencias de la salud, incluyendo la investigación y formación en la práctica clínica de la interrupción voluntaria del embarazo.

b) La formación de profesionales en salud sexual y salud reproductiva, incluida la práctica de la interrupción del embarazo.

c) La salud sexual y reproductiva en los programas de formación continuada a lo largo del desempeño de la carrera profesional.

d) En los aspectos formativos de profesionales de la salud se tendrán en cuenta la realidad y las necesidades de los grupos o sectores sociales más vulnerables, como el de las personas con discapacidad".

La reforma no podía dejar de tener consecuencias en la formación de los profesionales de la sanidad. Así, opta explícitamente por la perspectiva de género, que obedece a una determinada opción ideológica, la ideología de género, que está lejos de ser aceptada por la mayoría de la sociedad (Sánchez Cámara, 2011, pp. 240-243). Por lo demás, una ley democrática no debería imponer nunca una opción ideológica en el ámbito educativo. Eso es más bien propio de los sistemas totalitarios. Además, como no podía ser de otro modo, la ley obliga a incluir en los programas de las carreras sanitarias la práctica del aborto. Esta exigencia contraviene la deontología profesional de los médicos, que les obliga a proteger la vida y la salud de los pacientes, y no a acabar con ellas. La eliminación de la vida embrionaria viene así, por imperativo legal, a convertirse en parte necesaria del arte de la medicina. Eliminar embriones deviene parte de la finalidad de las profesiones sanitarias. El apartado b del artículo 8 incluye la práctica abortiva en la formación de los profesionales médicos. Viene a ser algo así como una especialidad médica más.

El artículo siguiente, el 9, establece una serie de medidas en el ámbito educativo:

"El sistema educativo contemplará la formación en salud sexual y reproductiva, como parte del desarrollo integral de la personalidad y de la formación en valores, incluyendo un enfoque integral que contribuya a:

a) La promoción de una visión de la sexualidad en términos de igualdad y corresponsabilidad entre hombres y mujeres con especial atención a la prevención de la violencia de género, agresiones y abusos sexuales. 
b) El reconocimiento y aceptación de la diversidad sexual.

c) El desarrollo armónico de la sexualidad acorde con las características de las personas jóvenes.

d) La prevención de enfermedades e infecciones de transmisión sexual y especialmente la prevención del VIH.

e) La prevención de embarazos no deseados, en el marco de una sexualidad responsable.

f) En la incorporación de la formación en salud y salud sexual y reproductiva al sistema educativo, se tendrán en cuenta la realidad y las necesidades de los grupos o sectores sociales más vulnerables, como el de las personas con discapacidad proporcionando, en todo caso, a este alumnado información y materiales accesibles, adecuados a su edad".

En definitiva, se trata de incorporar el aborto (ya que se considera como parte esencial de la salud sexual y reproductiva) al ámbito educativo. Una vez que se despenaliza el aborto, una vez que se transforma lo que es un delito en un derecho, no queda otro camino que llevar el despropósito al ámbito educativo. El apartado a del artículo 9 obliga a promover una visión de la sexualidad en términos de igualdad (cabe suponer que se trata de excluir la supremacía de un sexo sobre otro; tal vez bastaría entonces con una referencia a la libertad, más que a la igualdad) y de corresponsabilidad. Esto último lo dificulta en extremo la propia legislación. La mujer embarazada decide por sí sola, sin necesidad de contar en absoluto con la opinión del padre. ¿Cómo puede hablarse entonces de corresponsabilidad en el caso de que solo uno de los tres afectados decida? Por otra parte, si en el plazo legal de catorce semanas, la mujer puede decidir, sin invocar ningún motivo, la "interrupción del embarazo”, el varón tendrá siempre a mano la liberación de responsabilidad por la paternidad, ya que la mujer siempre habría podido deshacerse de la carga indeseada. Lo que favorece la ley, aparte de la eliminación libre de la vida humana, es la irresponsabilidad del varón. A menos que lo que se pretenda sea que el convidado de piedra a la decisión, se convierta después en corresponsable de una procreación que no ha decidido. Solo hay corresponsabilidad si hay codecisión. Si el varón no decide, no puede ser luego responsable. La nueva regulación es un monumento a la irresponsabilidad sexual del varón.

La mención a la prevención de la violencia de género, agresiones y abusos sexuales está muy bien, pero ya están prevenidos en el código penal. Por lo demás, el aborto no es pequeña agresión. Desde luego, al embrión, pero también a la mujer.

El apartado b impone en la educación "el reconocimiento y aceptación de la diversidad sexual". Una de dos. Si se refiere, lo que no parece, a la diferenciación sexual entre varón y mujer, se trata de una obviedad. Si la referencia a la diversidad sexual se refiere al reconocimiento y aceptación de todas las formas de sexualidad, se trata de algo inaceptable. No se puede imponer por ley una convicción, en este caso la de que todas las formas de sexualidad han de ser aceptadas y reconocidas por igual en el ámbito educativo. Por poner un ejemplo, no es lícito imponer la equiparación valorativa de la heterosexualidad y de la homosexualidad. Lo que sí se puede exigir es respeto para todas las personas con independencia de su orientación sexual, pero eso no entraña la equiparación jurídica y moral.

Otro de los aspectos de la reforma que ha suscitado viva controversia es el relativo al aborto realizado sobre menores, concretamente sobre mujeres de 16 y 17 años. El punto 4 del artículo 13, que es el que regula los requisitos del ejercicio del derecho al aborto, establece:

\footnotetext{
"En el caso de las mujeres de 16 y 17 años, el consentimiento para la interrupción voluntaria del embarazo les corresponde exclusivamente a ellas de acuerdo con el régimen general aplicable a las mujeres mayores de edad.
}

Al menos uno de los representantes legales, padre o madre, personas con patria potestad o tutores de las mujeres comprendidas en esas edades deberá ser informado de la decisión de la mujer.

Se prescindirá de esta información cuando la mujer alegue fundadamente que esto le provocará un conflicto grave, manifestado en el peligro cierto de violencia intrafamiliar, amenazas, coacciones, malos tratos, o se produzca una situación de desarraigo o desamparo".

Las mujeres de 16 y 17 años se tienen por mayores de edad a los efectos del aborto. No pueden votar o comprar tabaco o tomar un vino, pero sí pueden decidir abortar. No se requiere el permiso del padre, madre o tutor. Es una especie de privilegio abortivo. La ley establece la necesidad de informar (lo que ciertamente no es lo mismo que consentir o aceptar) a uno de los representantes legales. Incluso de esta información se puede prescindir si la menor alega el riesgo de un conflicto grave. La ley se refiere a que al menos uno de sus representantes legales "deberá ser informado de la decisión de la mujer", pero no dice 
nada acerca de las consecuencias del incumplimiento de ese deber. Se trata de un deber imperfectísimo, sobre cuyo incumplimiento no pesa la menor consecuencia jurídica. En definitiva, las mujeres de 16 y 17 años tienen también, de hecho, derecho al aborto. Ser informado no significa, evidentemente, tomar parte en la decisión. La mujer decide sola: sin sus padres y sin el padre 5 .

El artículo 19 establece las "medidas para garantizar la prestación por los servicios de salud". En su punto 2 se regula la objeción de conciencia de los profesionales sanitarios, después de asegurar el acceso a la prestación y de garantizar la igualdad y calidad asistencial de la prestación.

\footnotetext{
"La prestación sanitaria de la interrupción voluntaria del embarazo se realizará en centros de la red sanitaria pública o vinculados a la misma. Los profesionales sanitarios directamente implicados en la interrupción voluntaria del embarazo tendrán el derecho de ejercer la objeción de conciencia sin que el acceso y la calidad asistencial de la prestación puedan resultar menoscabadas [debería decir "menoscabados"] por el ejercicio de la objeción de conciencia. El rechazo o la negativa a realizar la intervención de interrupción del embarazo por razones de conciencia es una decisión siempre individual del personal sanitario directamente implicado en la realización de la interupción voluntaria del embarazo, que debe manifestarse anticipadamente y por escrito. En todo caso los profesionales sanitarios dispensarán tratamiento y atención médica adecuados a las mujeres que lo precisen antes y después de haberse sometido a una intervención de interrupción del embarazo".
}

El estatuto jurídico del derecho a la objeción de conciencia en nuestro ordenamiento es discutido. Para unos, creo que con mayor razón, se encuentra incluido en el derecho a la libertad ideológica y de conciencia y no necesita de su reconocimiento por cada ley particular sino que debe ser directamente reconocido por los tribunales. Otros piensan que compete a cada ley, en su caso, reconocerlo y regularlo, y no sería de aplicación automática por los tribunales. Existen sentencias en ambos sentidos. Es, pues, una cuestión disputada, aunque creo preferible la primera opción. En cualquier caso, esta ley recoge la objeción de conciencia de los profesionales de la sanidad, pero en términos muy restrictivos. Para empezar el ejercicio del derecho está supeditado a la condición de que "el acceso y la calidad de la prestación" no sufran menoscabo. Una vez más queda patente la configuración del aborto como derecho por la ley. No tendría senti- do que el derecho a la objeción de conciencia quedara limitado por algo que no fuera también un derecho. El aborto se configura como un derecho y además como uno que prevalece sobre el derecho a la objeción de conciencia. En definitiva, el "derecho" de la mujer a eliminar al embrión es preferido al derecho a la libertad de conciencia de los profesionales sanitarios. Además, la ley establece que la opción por la objeción de conciencia "debe manifestarse anticipadamente y por escrito". Esta obligación limita aún más el ejercicio del derecho, ya que excluye la objeción sobrevenida y obliga además a una declaración anticipada y por escrito que, con toda verosimilitud, vulnera el derecho a no hacer públicas las propias convicciones morales, ideológicas y religiosas. En conclusión, un médico será obligado a practicarlo en contra de su conciencia y de los principios deontológicos de su profesión, si, en caso de no hacerlo, la mujer no pueda satisfacer con garantías el acceso a la prestación del aborto. La conciencia personal y la deontología profesional valen mucho menos para nuestro derecho que la arbitraria decisión de la gestante de eliminar al embrión.

La aparente y falsa "invisibilidad" del embrión también facilita las cosas a los defensores del aborto. Por eso se irritan tanto cuando se exhiben imágenes que muestran la realidad del aborto. Acaso aquí resida también la mayor facilidad con la que se acepta la licitud del aborto frente a la mayor resistencia a la de la eutanasia. En conclusión, la nueva regulación del aborto como derecho entraña un paso decisivo más en el declive de la protección jurídica de la vida en el derecho español (Sánchez Cámara, 2011, pp. 83-131).

\section{CONCLUSIÓN}

El "derecho a abortar" no puede ser, como hemos visto, una exigencia liberal. Defender la vida del no nacido no es una actitud retrógrada ni fundamentalista, sino, por el contrario, lo más progresista en el sentido genuino del término. Tampoco se trata de una cuestión religiosa o de mera fe que divida a creyentes y no creyentes. Es cuestión de razón. La razón y la libertad bien entendida se expresan contra el aborto. Si existe un derecho a la vida, no puede haber un derecho a quitar la vida. El dictamen jurídico y el moral no tienen por qué coincidir. No todo lo inmoral merece la represión jurídica. El derecho se encuentra vinculado más bien a la moral social ${ }^{6}$. Es posible que una conducta inmoral deba ser permitida por el derecho. Pero no es este el caso del aborto porque no se trata de una decisión que pueda dejarse al arbitrio de la conciencia personal sino que afecta al derecho porque a 
este compete la protección de la vida. La protección jurídica no tiene por qué ser necesariamente penal. Pero no parece posible que pueda protegerse jurídicamente la vida sin ningún instrumento penal. Por mi parte, creo que el proyecto elaborado por el ministro Ruiz-Gallardón, que no llegó a prosperar, era una buena regulación del aborto.

Julián Marías afirmó, con razón, que los mayores errores morales del siglo XX habían sido la aceptación social del aborto y la generalización del consumo de drogas. A veces, no se ha entendido correctamente esta afirmación. No se trata de que no haya que incluir otras conductas igual de graves o incluso más, pero se trata, como sucede, por ejemplo, con los campos de exterminios nazis o soviéticos, de crímenes que, en general, se consideran como crímenes. En estos dos casos, se trata de conductas ampliamente aceptadas y que, por ello, constituyen errores morales. Un crimen no es un error moral: es una transgresión de la moral. Un error moral consiste en estimar como bueno lo que, de suyo, es malo.

El derecho descansa en la opinión pública. La formación de la opinión pública debe ser obra de una minoría ejemplar, pero la creación del derecho no. El derecho no puede estar al servicio de una minoría ejemplar, ni ser obra de ella. Para alcanzar la defensa jurídica de la vida, es preciso antes lograr que constituya una exigencia de la opinión pública. Se trata, por lo tanto, de una cuestión educativa. Antes de cambiar el derecho, hay que cambiar las conciencias.

\section{NOTAS}

1. “¿Qué es el Derecho? ¿Cómo debe ser el Derecho? Casi nadie se pregunta por lo primero, mientras que casi todos opinamos sobre lo segundo, a veces con mucha rotundidad, y no sólo con palabras, sino también con acciones u omisiones. Esta diferencia de actitud resulta chocante. Porque ¿cómo podemos saber lo que debe ser el Derecho sin tener una idea clara de lo que es? No queremos decir que no se tenga de él una cierta idea, más o menos confusa. Dos son las concepciones, más o menos ocultas o inconscientes, que parecen prevalecer: una, que el Derecho es algo equiparable a la moral o ética; otra, que no es más que el objeto de la política, de la lucha política, ya que en esta de lo que se trata es de determinar por quién y cómo se han de establecer las leyes y preceptos que han de regir la sociedad, es decir, el Derecho. Pero ambas lo desnaturalizan, deforman su verdadero ser, y con fatales consecuencias; porque dificultan el reconocimiento de los valores que verdaderamente le corresponden, y de la función que tiene que desempeñar el Derecho" (Rodríguez Paniagua, 2013, p. 9).

2. Para adentrarse en el estudio de una bioética personalista constituye una excelente guía el manual de Elio Sgreccia (2007).
3. El propio Mill lo expone así: “El objeto de este ensayo es afirmar un sencillo principio destinado a regir absolutamente las relaciones de la sociedad con el individuo en lo que tengan de compulsión o control, ya sean los medios empleados la fuerza física en forma de penalidades legales o la coacción moral de la opinión pública. Este principio consiste en afirmar que el único fin por el cual es justificable que la humanidad, individual o colectivamente, se entremeta en la libertad de acción de uno cualquiera de sus miembros, es la propia protección. Que la única finalidad por la cual el poder puede, con pleno derecho, ser ejercido sobre un miembro de la comunidad civilizada contra su voluntad, es evitar que perjudique a los demás. Su propio bien, físico o moral, no es justificación suficiente. Nadie puede ser obligado justificadamente a realizar o no realizar determinados actos, porque eso fuera mejor para él, porque le haría feliz, porque, en opinión de los demás, hacerlo sería más acertado o más justo. Estas son buenas razones para discutir, razonar y persuadirle, pero no para obligarle o causarle algún perjuicio si obra de manera diferente. Para justificar esto sería preciso pensar que la conducta de la que se trata de disuadirle producía un perjuicio a algún otro. La única parte de la conducta de cada uno por la que él es responsable ante la sociedad es la que se refiere a los demás. En la parte que le concierne meramente a él, su independencia es, de derecho, absoluta" (Mill, 1974 , p. 223 y p. 224 )

4. "Como es de sobra conocido, a pesar de los asombrosos avances de la ciencia médica, aún no es posible interrumpir un embarazo: o se le deja llegar a término o se acaba con él, pero no se interrumpe. Convertir el eufemismo en derecho subjetivo puede tener sus riesgos. Cualquier día una madre gestante exigirá interrumpir su embarazo en junio para retomarlo, pongamos por caso, en octubre, evitando de esta forma las molestias propias del calor veraniego durante la gestación" (Albert, 2013, p. 91).

5. La posibilidad de que las menores puedan abortar sin el consentimiento de los padres ha sido suprimida por una reforma del Gobierno del Partido Popular.

6. De la moral se puede hablar en tres sentidos fundamentales: la moral social, es decir, la vigente mayoritariamente en un grupo o en una sociedad; la moral de los sistemas filosóficos o religiosos; y la moral de la convicción personal. 


\section{BIBLIOGRAFÍA}

Abellán, F. (2010). Aspectos prácticos de la regulación del aborto. En Sánchez Caro, J. y Abellán, F. (coords.). Salud sexual y reproductiva. Aspectos científicos, éticos y jurídicos. Granada: Comares, pp. 126-145.

Albert, M. (2009). Relativismo ético, ¿̇absolutismo jurídico? Persona y Derecho, 61, pp. 33-52.

Albert, M. (2013). ¿Tenemos derecho a abortar? De la despenalización a la exigibilidad jurídica: el proceso de reforma legal del aborto en España. Revista de Derechos Humanos, 4, pp. 87-109.

Albert, M. (2015). Bioderecho y Bioética, ¿una "relación desnaturalizada"? En Santos, J. A. y Hermida del Llano, C. (coords.). Una filosofía del derecho en acción. Homenaje al profesor Andrés Ollero. Madrid: Congreso de los Diputados/Universidad Rey Juan Carlos, pp. 2272-2287.

Aznar, J. (2013). Defender la vida humana. En: Larrú, J. de D. (ed.). La grandeza del amor humano. Madrid: BAC, pp. 195-211.

Bellver Capella, V. (2014). Por un debate constructivo sobre el aborto. Claves de la razón práctica, 233, pp. 72-81.

D'Agostino, F. (2009). Introduzione alla biopolitica. Dodici voci fondamentali. Roma: Aracne.

García Maynez, E. (1977). Positivismo jurídico, realismo sociológico y iusnatu- ralismo. México: Universidad Nacional Autónoma de México.

González Marsal, C. (2009). Sexualidad y aborto, ¿cuestión de salud?, ¿cuestión de derechos? Anuario de Derechos Humanos. Nueva Época, 10, pp. 285-329.

Ihering, R. von (1998). El espíritu del Derecho Romano en las diversas fases de su desarrollo. Granada: Comares.

Kelsen, H. (2006). De la esencia y valor de la democracia. Oviedo: Ediciones KRK.

Mill, J. S. (1974). On Liberty. En Collected Works of John Stuart Mill (vol. XVIII). Toronto: The University of Toronto Press / Londres: Routledge and Kegan Paul, pp. 213-310.

Ollero, A. (2006). Bioderecho. Entre la vida y la muerte. Cizur Menor / ThomsonAranzadi.

Ollero, A. (2010, 31 de enero). El aborto y el Tribunal Constitucional. Diario Médico.

Requero Ibáñez, J. L. (2009). La reforma de la legislación del aborto en España. Cuadernos de Bioética, 20 (3), pp. 487-501.

Rodríguez Paniagua, J. M. (1985). Lecciones de Derecho Natural como Introducción al Derecho. Madrid: Universidad Complutense.

Rodríguez Paniagua, J. M. (2013). Historia del pensamiento jurídico. 1. De Herá- clito a la Revolución francesa. Madrid: Biblioteca Nueva.

Sánchez Cámara, I. (1999). Los derechos humanos, entre la retórica y la ideología. Derecho y Opinión, pp. 669-672.

Sánchez Cámara, I. (2011). La familia. La institución de la vida. Madrid: La Esfera de los Libros.

Sánchez Cámara, I. (2012). De delito a derecho. El declive de la protección jurídica de la vida. Cuadernos de Bioética, 23 (1), pp. 25-36.

Sánchez Cámara, I. (2015). Democracia y relativismo ético. En Santos, J. A. y Hermida del Llano, C. (coords.). Una filosofía del derecho en acción. Homenaje al profesor Andrés Ollero. Madrid: Congreso de los Diputados/Universidad Rey Juan Carlos, pp. 1143-1157.

Serrano Ruiz-Calderón, J. M. (2005). Despenalización, legalización. En Serrano Ruiz-Calderón, J. M. Retos jurídicos de la bioética. Ediciones Internacionales Universitarias, pp. 162-177.

Sgreccia, E. (2007). Manuale di bioética (vol. 1. Fondamenti ed ética biomédica). Milano: Vita e Pensiero.

Wolf, E. (1950). El problema del derecho natural Barcelona: Ariel. 